\title{
Metabolic Habituation Following Repeated Resting Cold-Water Immersion Is Not Apparent During Low-Intensity Cold-Water Exercise
}

\author{
Jodie M. Stocks ${ }^{1)}$, Mark J. Patterson ${ }^{1)}$, Dale E. Hyde ${ }^{2)}$, \\ Karen D. Mittleman ${ }^{3)}$ and Nigel A.S. Taylor ${ }^{1)}$ \\ 1) Department of Biomedical Science, University of Wollongong, N.S.W., Australia \\ 2) Naval Experimental Diving Unit, Florida, U.S.A. \\ 3) DesignWrite, New Jersey, U.S.A.
}

\begin{abstract}
This project examined the effects of repeated, resting cold-water immersion on metabolic heat production and core temperature defence during subsequent rest and exercising immersions. Seven males undertook 15 days of cold-water adaptation, immersed to the fourth intercostal space, with cold-water stress tests (CWST) on days 1,8 and $15\left(18.1 \mathrm{SD} 0.1^{\circ} \mathrm{C}\right.$ : $60 \mathrm{~min}$ seated, followed by $30 \mathrm{~min}$ cycling $\left.\left(1 \mathrm{~W} \cdot \mathrm{kg}^{-1}\right)\right)$, and $90-\mathrm{min}$ resting immersions $\left(18.4 \mathrm{SD} 0.4^{\circ} \mathrm{C}\right)$ on each of the intervening days. Adaptation elicited an habituated thermogenic response during the rest phase of CWST3 beyond $20 \mathrm{~min}$, compared to CWST1 $(P<0.05)$, with oxygen consumption averaging $11.15( \pm 0.25) \mathrm{ml} \cdot \mathrm{kg}^{-1} \mathrm{~min}^{-1}$ and $8.61( \pm 0.90) \mathrm{ml} \cdot \mathrm{kg}^{-1} \cdot \mathrm{min}^{-1}$ by $50 \mathrm{~min}$, for CWST1 and CWST3, respectively. During exercise, this metabolic blunting was only apparent over the first 10-min period (60-70 min). No significant differences were observed during either the rest or exercise phases of the CWSTs for oesophageal temperature $\left(\mathrm{T}_{\mathrm{es}}\right)$. While repeated coldwater exposures produced an habituated-thermogenic response, for an equivalent drop in $\mathrm{T}_{\mathrm{es}}$ during rest, neither this response, nor an elevated thermogenesis, were apparent during subsequent cold-water exercise. $J$ Physiol Anthropol 20 (5): 263-267, 2001 http:// www.jstage.jst.go.jp/en/
\end{abstract}

Keywords: acclimation, cold, exercise, habituation, immersion

\section{Introduction}

Water offers negligible thermal insulation at the skin surface, and during cold immersion, skin temperature
$\left(\mathrm{T}_{\text {sk }}\right)$ rapidly falls towards water temperature (Nadel, 1977). Notwithstanding this lower $\mathrm{T}_{\mathrm{sk}}$, more rapid convectional heat losses occur, with $\mathrm{T}_{\mathrm{c}}$ falling two-five times more quickly compared with that observed in air at the same temperature (Hong, 1984). When immersion is accompanied by exercise, the rate of $\mathrm{T}_{\mathrm{c}}$ decline is often (Cannon and Keatinge, 1960; Keatinge, 1961), though not always accelerated (Craig and Dvorak, 1968; McArdle et al., 1984). This disparity stems not only from differences in water temperature and subject adiposity, but from variations in both exercise intensity and mode. Certainly, low-intensity exercise may accelerate $\mathrm{T}_{\mathrm{c}}$ decline, relative to the resting state, as it disturbs the trapped boundary layer, reduces total insulation due to an elevated muscle blood flow, and increases the exposed skin surface area. The current investigation focussed upon such lowintensity exercise, with particular attention to the effects of repeated resting cold-water immersion upon metabolic heat production (thermogenic response) and $\mathrm{T}_{\mathrm{c}}$ defence during subsequent cold-water exercise.

Thermal adaptations which enhance survival take morphological, physiological, biochemical, and behavioural forms (Werner, 1994). For instance, during shorter-term heat adaptation, thermoeffector function is enhanced, as typified by an enhanced sweating response (Nadel et al., 1974; Libert et al., 1983); a positive phenotypic adaptation (Mekjavić and Bligh, 1987). However, repeated cold exposures can elicit either positive (acclimation) or negative (habituation) adaptation (Young, 1996). Humans may display three distinct, but not necessarily exclusive, adaptation patterns, including: metabolic, insulative and hypothermic adaptation (Hammel, 1963). The metabolic adaptation is typified by an increased metabolic heat 
production (Keatinge, 1961; Scholander et al., 1958), and is observed in many species (Feist and White, 1989), but is infrequently seen in humans. The insulative adaptation response is characterised by a lower skin temperature during cold stress, while $\mathrm{T}_{\mathrm{c}}$ and metabolic rate remain near pre-exposure levels (Hong, 1973; Park et al., 1983). Hypothermic adaptation is associated with a greater fall in $\mathrm{T}_{\mathrm{c}}$ and an habituated metabolic heat production (Brück et al., 1976; Young et al., 1986), and was classically described in Australian Aborigines (Hicks and Matters, 1933). This response is most common following intermittently-applied cold exposure, such as that employed by the current study. In this report, we address the interaction of such a metabolic habituation upon $\mathrm{T}_{\mathrm{c}}$ defence during post-adaptation, cold-water exercise.

Only one group has previously addressed the possible carry-over effects from resting cold adaptation into a subsequent exercising cold exposure (Golden and Tipton, 1988). Using a short, rigorous regimen, Golden and Tipton (1988) found no significant adaptation differences during exercise immersion when compared prior to, and following, six resting cold-water immersions $\left(15^{\circ} \mathrm{C}, 40\right.$ min). Since an habituated-metabolic response, accompanied by a greater fall in $\mathrm{T}_{\mathrm{c}}$, was apparent on the final adaptation day, it was postulated that exercise obscured the possible benefits of the resting adaptation, accelerating heat loss in excess of heat conservation (Golden and Tipton, 1988). However, it is possible that six immersions were too few to allow this habituation response to manifest itself during exercise. Since the authors did not report $\mathrm{T}_{\mathrm{c}}$ across adaptation days, the thermal strain remained unquantified. In addition, it is not known whether the cold-water exercise response was protocol specific, or was generalised across adaptation regimens eliciting different thermal strain levels. To evaluate these issues in the current investigation, we increased the duration of each cold exposure, eliciting an average rectal temperature $\left(\mathrm{T}_{\mathrm{re}}\right)$ reduction of $1.87^{\circ} \mathrm{C}$, we doubled the number of consecutive cold exposures, and we studied both rest and exercise within a single experimental session, to better observe the possible carry over of a resting metabolic habituation into the exercising state.

\section{Methods}

Seven healthy, active males (24.7 SD 8.7 yr; mass 74.4 SD $6.4 \mathrm{~kg}$; height $176.8 \mathrm{SD} 7.8 \mathrm{~cm}$; sum of eight skinfolds 107.4 SD $20.4 \mathrm{~mm}$ ), participated in this study during the Autumn months, which was approved by the University of Wollongong's Human Experimentation Ethics Committee. Subjects were exposed to cold-water stress tests (CWST), immersed to the fourth intercostal space (seated), in well-stirred water, on days 1, 8 and 15 of a 15- d cold-water adaptation protocol $\left(18.1^{\circ} \mathrm{C}\right.$ SD $0.1^{\circ} \mathrm{C}$, air temperature $21.3^{\circ} \mathrm{C} \mathrm{SD} 0.9^{\circ} \mathrm{C}$ ). Each CWST consisted of two phases: seated, slightly reclined rest (60 min); followed by cycling in the same posture (30 min at $1 \mathrm{~W} \cdot \mathrm{kg}^{-1}$; Collins Pedalmate, Warren E. Collins Inc., MA). The workload range corresponding with this relative intensity was $62-82 \mathrm{~W}$, and is indicative of the routine work intensity of military divers. Cold-water adaptation began the day following CWST1, and continued on days 2-7 and 9-14. Acclimation involved 90-min, cold-water immersions $\left(18.4^{\circ} \mathrm{C} \mathrm{SD} 0.4^{\circ} \mathrm{C}\right.$, air temperature $21.3^{\circ} \mathrm{C} \mathrm{SD}$ $1.0^{\circ} \mathrm{C}$ ), with the subjects seated at rest at the same immersion depth. Subjects wore only swimming costumes for all exposures.

On CWST days, fasting, euhydrated subjects were fed (38 kJ.kg ${ }^{-1} ; 7 \mathrm{ml} \cdot \mathrm{kg}^{-1}$ fluid) and rested $4.5 \mathrm{~h}$, in an air temperature of approximately $22^{\circ} \mathrm{C}$, before baseline data were collected. Body core (oesophagus and rectum) and skin temperatures were measured $(1 \mathrm{~Hz})$. The oesophageal temperature $\left(\mathrm{T}_{\mathrm{es}}\right.$ ) thermistor (Edale Instruments, Cambridge, U.K.) was inserted $\sim 40 \mathrm{~cm}$ from the nares (Mekjavić and Rempel, 1990). Rectal temperature $\left(\mathrm{T}_{\mathrm{re}}\right)$ was monitored $12 \mathrm{~cm}$ beyond the anal sphincter (Yellow Springs Instruments Co. Inc., Yellow Springs, $\mathrm{OH}$ ), and was also measured during acclimation days. Skin temperatures were measured using thermistors at eight sites: forehead, scapula, upper chest, upper arm, forearm, hand, thigh and calf (EU type, Yellow Springs Instruments Co. Inc., Yellow Springs, OH). Thermistors were calibrated against a certified reference thermometer (Dobbie Instruments, Sydney, Australia), and temperatures were recorded using a portable data logger (Grant Instruments Ltd., U.K.). Mean skin temperature $\left(\overline{\mathrm{T}}_{\mathrm{sk}}\right)$ was determined as an area-weighted average (International Standards Organisation, 1992), while mean body temperature $\left(\overline{\mathrm{T}}_{\mathrm{b}}\right)$ was derived: $\overline{\mathrm{T}}_{\mathrm{b}}=$ $\left(0.67{ }^{\star} \overline{\mathrm{T}}_{\mathrm{es}}\right)+\left(0.33^{\star} \overline{\mathrm{T}}_{\mathrm{sk}}\right)$. Oxygen consumption $\left(\dot{\mathrm{V}}_{\mathrm{O} 2}\right)$ was measured every 10 min during immersion, over a 3-min period (Quinton Instrument Company, Q-Plex I, Seattle, WA). Cardiac frequency $\left(f_{\mathrm{c}}\right)$ was recorded at $0.2 \mathrm{~Hz}$ (Polar Electro SportTester, model PE3000, Finland).

Multifactorial, repeated-measures analysis of variance was used to determine differences between acclimation trials (CWST1, 2 and 3 ) and across exposure time. Tukey's WSD test was used to isolate significant differences, with alpha set at 0.05. Unless otherwise stated, data are reported as means with standard errors of the means.

\section{Results}

All subjects completed every exposure, without early termination, experiencing a mean $\mathrm{T}_{\mathrm{re}}$ change, across adaptation days, of $-1.87^{\circ} \mathrm{C}( \pm 0.20)$. On the CWST days, the respective pre-exposure (baseline) for $\mathrm{T}_{\mathrm{es}}$ and $\mathrm{T}_{\mathrm{re}}$ 
remained unchanged, with progressive declines observed during the course of each CWST $(P<0.05)$. Due to the separate rest and exercise phases, two distinct $\mathrm{T}_{\mathrm{c}}$ responses were evident within each CWST. The 60-min resting phase elicited an initial $\mathrm{T}_{\text {es }}$ rise (Fig. 1), which is typically observed upon suddenly moving to a cooler temperature. Cold-induced vasoconstriction is maximal under such conditions, instantaneously reducing heat loss by elevating tissue insulation, decreasing conductive heat transfer, and minimising exposure of blood to the cold. These events precede shivering, positively disturbing heat balance (Hardy, 1954). This transient $\mathrm{T}_{\mathrm{es}}$ rise was followed by an approximately linear decline, producing a mean drop of $-0.52^{\circ} \mathrm{C}( \pm 0.07)$ across the three CWSTs (Figure 1). During the CWSTs, $\mathrm{T}_{\mathrm{re}}$ showed a significantly larger decrease, averaging $-1.16^{\circ} \mathrm{C}( \pm 0.14)$. Despite absolute differences between $\mathrm{T}_{\mathrm{c}}$ measurement sites, adaptation did not produce significant differences in either the $\mathrm{T}_{\mathrm{es}}$ or $\mathrm{T}_{\mathrm{re}}$ responses between CWST days $(P>0.05$, Fig. 1).

During the 30-min exercise period, further biphasic decreases in $\mathrm{T}_{\text {es }}$ occurred, with changes of $-0.55^{\circ} \mathrm{C}( \pm$ $0.15),-0.62^{\circ} \mathrm{C}( \pm 0.15)$, and $-0.65^{\circ} \mathrm{C}( \pm 0.16)$, following CWST1, 2, and 3, respectively (Figure 1; $P>0.05$ ). Average decreases in $\mathrm{T}_{\mathrm{re}}$ were: $-0.58^{\circ} \mathrm{C}( \pm 0.14),-0.84^{\circ} \mathrm{C}$ $( \pm 0.11)$, and $-0.68^{\circ} \mathrm{C}( \pm 0.12)$ following CWST 1,2 , and 3 , respectively. Final $\mathrm{T}_{\text {es }}$ were: $35.78^{\circ} \mathrm{C}( \pm 0.18$, CWST 1$)$, $35.80^{\circ} \mathrm{C}( \pm 0.23$, CWST2 $)$ and $35.74^{\circ} \mathrm{C}( \pm 0.19$, CWST3; $P>0.05$; Figure 1), demonstrating that the $15-\mathrm{d}$ resting acclimation regimen did not provide a thermal benefit, in terms of $\mathrm{T}_{\mathrm{c}}$ defence, during subsequent cold-water exercise.

Following the rest phase, $\overline{\mathrm{T}}_{\mathrm{sk}}$ remained unchanged during exercise, and was not significantly different between CWSTs $(P>0.05)$. Furthermore, no differences were observed in $\overline{\mathrm{T}}_{\mathrm{b}}$, or the temperature gradient between $\mathrm{T}_{\mathrm{es}}$ and the immersed $\overline{\mathrm{T}}_{\mathrm{sk}}(P>0.05)$. Evidently, tissue heat conductance, beyond the first 5-10 min, remained relatively constant during the exercise phase of each CWST, despite repeated cold-water exposure. Beyond the initial, cold-induced tachycardia, cardiac frequency decreased during immersion, and was significantly lower during the resting phase of CWST3 compared to CWST1, at 30 and $40 \mathrm{~min}$ of immersion $(P<0.05)$. Exercise produced a return of $f_{\mathrm{c}}$ to pre-immersion resting levels, mirroring the increased metabolic demand of the active muscles. However, no acclimation-induced response differences were observed for $f_{\mathrm{c}}$ during this phase of the CWSTs $(P>0.05)$.

Although $\dot{\mathrm{O}}_{\mathrm{O} 2}$ increased within the resting phase of each CWST, shivering thermogenesis was blunted (habituated) during the resting phase of CWST3, compared to CWST1 beyond 20 min $(P<0.05$; Figure 2$)$. Exercise induced further $\dot{\mathrm{V}}_{\mathrm{O} 2}$ increases in all CWSTs. However, a significant metabolic blunting during exercise was only apparent at

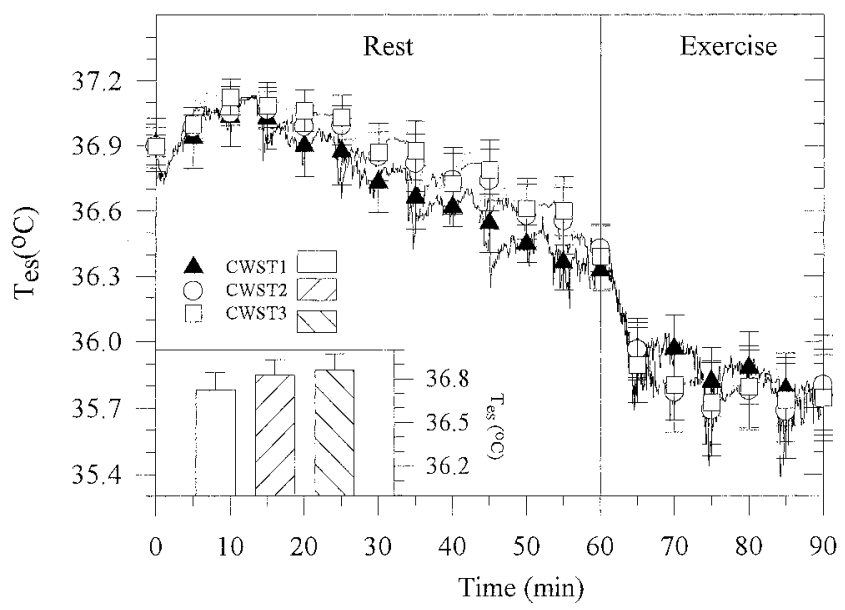

Fig. 1 Oesophageal temperature $\left(\mathrm{T}_{\mathrm{es}}\right)$ during 90-min, cold-water stress tests (CWST: $18.1^{\circ} \mathrm{C}$ ) on days one, eight and 15 of coldwater acclimation $\left(90\right.$-min rest; $\left.18.5^{\circ} \mathrm{C}\right)$. Insert shows $\mathrm{T}_{\text {es }}$ averaged over the rest phase of each CWST.

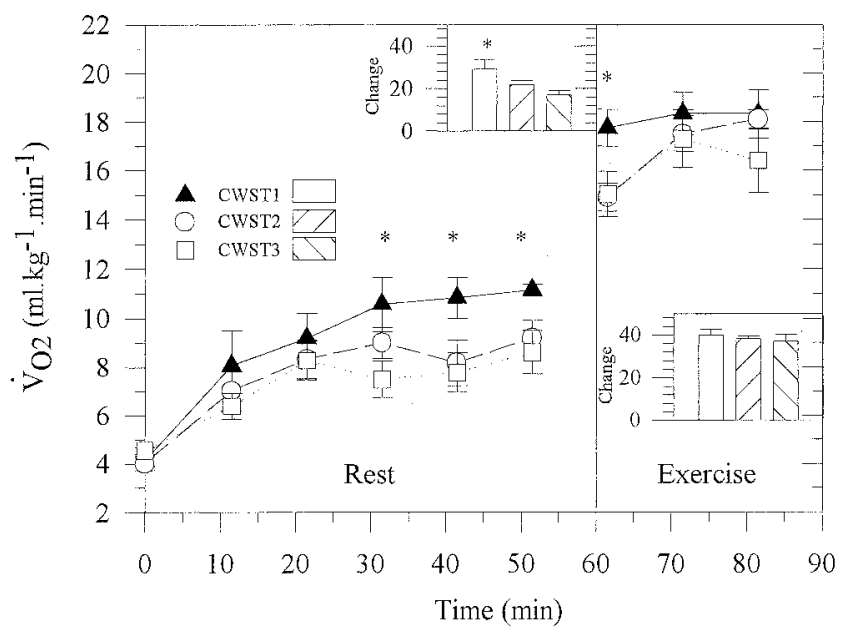

Fig. 2 Oxygen consumption $\left(\dot{\mathrm{V}}_{\mathrm{O} 2}\right)$ during 90-min cold-water stress tests (CWST: $18.1^{\circ} \mathrm{C}$ ) on days one, eight and 15 of cold-water acclimation (90-min rest; $18.5^{\circ} \mathrm{C}$ ). Inserts show cumulative $\dot{\mathrm{V}}_{\mathrm{O} 2}$ change $\left(\mathrm{ml} \cdot \mathrm{kg}^{-1} \cdot \mathrm{min}^{-1}\right)$ from pre-immersion and pre-exercise baselines. Significant differences: ${ }^{*}=$ between CWST1 and 3 .

the first sampling point, reflecting the residual affects of metabolic habituation during the previous $60 \mathrm{~min}$ of resting immersion. Beyond this time, $\dot{\mathrm{O}}_{\mathrm{O} 2}$ was equivalent between trials ( $P>0.05$; Fig. 2$)$.

\section{Discussion}

This is only the second investigation to evaluate the effects of cold-water habituation upon thermal homeostasis during subsequent cold-water exercise (Golden and Tipton, 1988). The current investigation utilised a longer adaptation regimen, and increased the 
thermal impulse, demonstrating that during the 60-min rest phase of CWST3, there was a pronounced blunting of cold-induced thermogenesis, which occurred concomitantly with an equivalent $\mathrm{T}_{\mathrm{c}}$ defence. While such metabolic habituation is not a novel observation (Golden and Tipton, 1988; Janský et al., 1996), it is usually associated with greater falls in $\mathrm{T}_{\mathrm{c}}$. In addition, it was found that this habituation was apparently overridden during post-adaptation, low intensity cold-water exercise.

In the resting state, under the current conditions, it is possible that $\mathrm{T}_{\mathrm{c}}$ maintenance was facilitated primarily by increasing tissue insulation, which occurred concomitantly with an habituated metabolic response. Muscle accounts for about $80 \%$ of total body insulation for resting subjects in cool water (Veicsteinas et al., 1982). Shivering not only disturbs the boundary layer, but facilitates heat loss by increasing muscle perfusion. Thus, if the water temperature is low enough, then a slight elevation in shivering may actually increase heat loss more than it does heat production (Tipton; personal communication). It is possible that, under these circumstances, a dampened thermogenic response may itself serve a protective function, by minimising the $\mathrm{T}_{\mathrm{c}}$ reduction that would normally accompany cold stress. During exercise, convective cooling is dramatically elevated as the cycle cadence rhythmically displaces water close to the skin, and further increases muscle blood flow, thus eliciting the biphasic $\mathrm{T}_{\mathrm{es}}$ reduction (Fig. 1). In this circumstance, a blunted metabolic response would reduce net heat production, compromising thermal balance. In the current study, shivering and exercise-induced thermogenesis were insufficient to offset heat loss, and $\mathrm{T}_{\mathrm{c}}$ declined rapidly, and at a rate equal to that observed prior to adaptation. Thus, under circumstances where enhanced thermogenesis could have proven beneficial, it was still not evident. Furthermore, while it is possible that the resting metabolic adaptation was obscured during exercise (Golden and Tipton, 1988), there was no evidence of a blunted thermogenic response while subjects exercised in cold water, with both $\mathrm{T}_{\mathrm{es}}$ and $\dot{\mathrm{V}}_{\mathrm{O} 2}$ being equivalent to the values observed during CWST1. Therefore, no indication was apparent for any form of metabolic adaptation during the exercise phase.

Using the above data in conjunction with the heat balance equation, and assuming a constant tissue insulation, it was predicted that the $\mathrm{T}_{\mathrm{c}}$ decline could have been countered, had the work rate been increased to approximately 1.3 watts $\mathrm{kg}^{-1}$. However, in the absence of either a work rate elevation, or a greater adaptationinduced thermogenesis, a progressive $\mathrm{T}_{\mathrm{c}}$ decline for the current subjects would have occurred under all thermal states where water temperature was less than about 21$22^{\circ} \mathrm{C}$.

It is concluded that, while a longer cold-water adaptation regimen acts to attenuate the metabolic response for an equivalent drop in $\mathrm{T}_{\mathrm{c}}$ at rest in the cold, it has minimal impact upon shivering thermogenesis during cold-water exercise of low intensity. Thus, across a range of levels and durations of imposed thermal strain during resting cold-water adaptation, it appears that the metabolic responses observed during cold-water exercise appear to be similar before and after adaptation.

Acknowledgments This investigation was supported by funding from the Naval Medical Research Institute (U.S.A.). However, the opinions expressed in this paper are those of the authors, and do not reflect the official policy or position of the Department of the Navy, Department of Defense, or the U.S. Government. This study was submitted by J.M. Stocks in partial fulfilment of requirements for the Ph.D. degree in Biomedical Science from the University of Wollongong, Australia. J.M. Stocks was funded by ABSTUDY (Department of Employment, Education and Training, Australia), and M.J. Patterson by the University of Wollongong (Postgraduate Scholarship), during the completion of this project. The authors would like to thank Olivier de Hon and Lieske Hofland for their technical assistance, and the subjects for participating in the study. We also thank Dr. John Greenleaf for reviewing the manuscript.

\section{References}

Brück K, Baum E, Schwennicki HP (1976) Cold-adaptive modifications in man induced by repeated short-term cold exposures and during a 10-day and -night cold exposure. Pflügers Archiv 363: 125-133

Cannon P, Keatinge WR (1960) The metabolic rate and heat loss of fat and thin men in heat balance in cold and warm water. J Physiol 154: 329-344

Craig AB, Dvorak M (1968) Thermal regulation of man exercising during water immersion. J Appl Physiol 25: 28-35

Feist DD, White RG (1989) Terrestrial mammals in cold. In Wang $\mathrm{LCH}$ ed. Advances in comparative and environmental physiology. Springer-Verlag, Berlin, 327-360

Golden FStC, Tipton MJ (1988) Human adaptation to repeated cold immersions. J Physiol 396: 349-363

Hammel HT (1963) Summary of comparative thermal patterns in man. Fed Proc 22: 846-847

Hicks CS, Matters RF (1933) The standard metabolism of the Australian Aborigines. Aust J Exp Biol Med Sci 11: 177-183

Hong SK (1973) Pattern of cold adaptation in women divers of Korea (Ama). Fed Proc 32: 1614-1622

Hong SK (1984) Thermal considerations. In Shilling CW, Carlson CB, Mathias RA eds. The physician's guide to diving medicine. Plenum Press, New York, London, 
$153-178$

International Organisation for Standardisation (1992)

Evaluation of thermal strain by physiological measurements. ISO 9886: 1992 [E] Geneve, Switzerland

Janský L, Janáková H, Uličny B, Šármek P, Hošek V, Heller J, Pařízková J (1996) Changes in thermal homeostasis in humans due to repeated cold water immersions. Pflugers Arch 432: 368-37

Keatinge WR (1961) The effect of repeated daily exposure to cold and of improved physical fitness on the metabolic and vascular responses to cold air. J Physiol 157: 209-220

LeBlanc J (1978) Adaptation of man to cold. In Wang LCH, Hudson JW eds. Strategies in cold: natural torpidity and thermogenesis. Academic Press, New York, 695-715

Libert JP, Candas V, Vogt JJ (1983) Modifications of sweating responses to thermal transients following heat acclimation. Eur J Appl Physiol 50: 235-246

McArdle WD, Magel JR, Gergley TJ, Spina RJ, Toner MM (1984) Thermal adjustment to cold-water exposure in resting men and women. J Appl Physiol 56: 1565-1571

Mekjavić IB, Bligh J (1987) The pathophysiology of hypothermia. Int Rev Ergon 1: 201-218

Mekjavić IB, Rempel ME (1990) Determination of esophageal probe insertion length based on standing and sitting height. J Appl Physiol 69: 376-379

Nadel ER (1977) Thermal and energetic exchanges in swimming. In Nadel ER ed. Problems with temperature regulation during exercise Academic Press, New York, 91-119

Nadel ER, Pandolf KB, Roberts MF, Stolwijk JAJ (1974)
Mechanisms of thermal acclimation to exercise and heat. J Appl Physiol 37: 515-520

Park YS, Rennie DW, Lee IS, Park YD, Paik KS, Kang DH, Suh DJ, Lee SH, Hong SY, Hong SK (1983) Time course of deacclimatization to cold water immersion in Korean women divers. J Appl Physiol 54: 1708-1716

Scholander PF, Hammel HT, Andersen KL, Loyning Y (1958) Metabolic acclimation to cold in man. J Appl Physiol 12: 1-8

Veicsteinas A, Ferretti G, Rennie DW (1982) Superficial shell insulation in resting and exercising men in cold water. J Appl Physiol 52: 1557-1564

Werner J (1994) Beneficial and detrimental effects of thermal adaptation. In Zeisberger E, Schönbaum E, Lomax P eds. Thermal balance in health and disease. Advances in pharmacological sciences. Birkhäuser Verlag, Basel, 141-154

Young AJ (1996) Homeostatic responses to prolonged cold exposure: Human cold acclimatization. In Fregly MJ, Blatteis CM eds. Handbook of physiology. Section 4: Environmental physiology. Vol 1. Oxford University Press, New York, 419-438

Young AJ, Muza SR, Sawka MN, Gonzalez RR, Pandolf KB (1986) Human thermoregulatory responses to cold air are altered by repeated cold water immersion. J Appl Physiol 60: 1542-1548

Received: December 18, 2000

Accepted: June 20, 2001

Correspondence to: Nigel A.S. Taylor, Department of Biomedical Science, University of Wollongong, Wollongong, N.S.W. 2522, Australia

e-mail: nigel_taylor@uow.edu.au 